J. Lake Sci. (湖泊科学), $2006, \mathbf{1 8}(5): 503-508$

http:// www. jlakes. org. E-mail: jlakes@ niglas. ac.cn

(c) 2006 by Journal of Lake Sciences

\title{
基于富营养化阈值的松花湖水环境容量分析”
}

\author{
王 霞 ${ }^{1,2}$, 吕宪国 ${ }^{2}$, 阇伯茹 ${ }^{1}$, 于 力 $^{1}$, 张竹青 ${ }^{1}$, 张丽娴 ${ }^{1}, 弓$ 学林 ${ }^{2}$ \\ (1: 吉林省环境监测中心站, 长春 130011) \\ (2: 中国科学院东北地理与农业生态研究所, 长春 130012)
}

摘 要: 通过对松花湖水体中浮游植物的绝对优势种——铜绿微囊藻 (Microcystis aeruginosa) 单藻株生长与磷、氮定量关 系的室内模拟研究,得出松花湖富营养化发生的阈值为: 总磷浓度 $0.065 \mathrm{mg} / \mathrm{L}$, 总氮浓度 $0.843 \mathrm{mg} / \mathrm{L}$. 利用风险分析理论 和蒙特卡罗随机模拟方法,在分析 $2002-2004$ 年松花湖水体中总磷和总氮浓度实际分布规律的基础上,提出了计算湖、 库总磷和总氮水环境容量的不确定性方法. 通过对松花湖磷、氮水环境容量的计算,得出松花湖流域总磷和总氮的最大允 许排放量为 $2123.78 \mathrm{t} / \mathrm{a}$ 和 $7018.82 \mathrm{t} / \mathrm{a}$, 为了使松花湖富营养化发生的概率在 0.001 以下, 总磷和总氮需要分别削减 $3208.34 \mathrm{t} / \mathrm{a}$ 和 $18648.91 \mathrm{t} / \mathrm{a}$.

关键词: 水环境容量; 富营养化; 阈值; 松花湖

\section{On the water environmental capacity of Lake Songhua based on eutrophication threshold}

\author{
WANG Xia ${ }^{1,2}$, LU Xianguo ${ }^{2}$, YAN Bairu ${ }^{1}, \mathrm{YU} \mathrm{Li}^{1}$, ZHANG Zhuqing ${ }^{1}$, ZHANG Lixian ${ }^{1} \&$ ZHANG Xuelin ${ }^{2}$ \\ (1: Environment Monitoring Center of Jilin Province, Changchun 130011, P. R . China) \\ (2: Northeast Institute of Geography and Agricultural Ecology, CAS, Changchun 130012, P. R . China)
}

\begin{abstract}
The water environmental capacity of phosphorus and nitrogen is an important factor to control water eutrophication in lakes/reservoirs. The quantitative connection between the growth of predominant species i. e. unialgat strain of Microcystis aeruginosa and the concentration of TP and TN in Lake Songhua was studied in the laboratory using simulation method. Results indicated that TP threshold is $0.065 \mathrm{mg} / \mathrm{L}$, TN threshold is $0.843 \mathrm{mg} / \mathrm{L}$ in the Lake Songhua. Risk assessment theory and Monte Carlo method were employed to analyze the concentration distribution regulation of TP and TN in the lake based on the data from 2002 to 2004 . The paper developed an uncertainty method to calculate water environmental capacity of TP and TN in lakes / reservoirs. Because the uncertainty method was based on water self-purification law, and it isn' $t$ needed to calculate some parameters difficult to identify, such as the degradation coefficient of the pollutants. It is useful to calculate the water environmental capacity of TP and TN in the Lake Songhua with the uncertainty methods. The result indicated that the maximum permissible discharge amounts of TP and TN in the Lake Songhua watershed were $2123.78 \mathrm{t} / \mathrm{a}$ and $7018.82 \mathrm{t} / \mathrm{a}$. In order to control that eutrophication probability in the Lake Songhua was below 0.001, amounts of TP and TN were need to decrease 3208.34 t/a and $18648.91 \mathrm{t} / \mathrm{a}$, respectively.
\end{abstract}

Keywords : Water environmental capacity; eutrophication; threshold; Lake Songhua

湖泊、水库富营养化是目前国内外环境科学领域关注的热点,也是我国面临严峻的水环境问题. 磷、氮 是湖、库水体富营养化的主要影响因子, 湖库磷、氮水环境容量是水体富营养化控制的重要依据 ${ }^{[1,2]}$. 由于 目前对富营养化发生机理的研究还不充分, 所以富营养化的量化、定义尚不明了; 另外, 我国的水体富营养 化标准不能简单地套用欧洲等其它国家的标准 ${ }^{[3]}$, 所以研究湖库富营养化发生的机理, 明确不同湖、库富

* 吉林省环境保护局项目 (吉环科字 $00-02$ 号) 和中国科学院东北地理与农业生态研究所学科前沿领域项目 ( KZCX3 - SW - NA - 01) 联合资助. 2005-08-22 收稿;2005-12-04 收修改稿. 王霞, 女, 1970 生, 博士, 高级工 程师,E-mail: wangxia123@ hotmail.com. 
营养化发生的阈值尤为重要. 本研究结合实验室模拟的结果给出富营养化发生的阈值, 以 $2002-2004$ 年松 花湖水体各种形态磷和氮的特征为依据, 再结合各种形态磷和氮被藻类利用的分析, 得出水体中生物可利 用磷和氮与总磷和总氮的定量关系, 从而得到松花湖水体总磷和总氮的控制目标.

由于湖泊和水库磷、氮受纳、迁移、转化过程非常复杂, 影响因素很多, 所以根据实测的各项水质指标浓 度等多个不确定性信息, 采用适宜的不确定模型或方法来预测磷、氮显得非常必要 ${ }^{[4]}$. 目前, 利用非确定性 模型计算湖、库总磷、总氮水环境容量的研究还不多见 ${ }^{[5]}$. 本研究在风险分析理论和蒙特卡罗随机模拟计 算的基础上, 充分考虑松花湖磷、氮实际自净能力和浓度分布规律, 提出在一定保证率水质达标情况下湖库 总磷、总氮水环境容量的计算方法, 以期为松花湖水体磷、氮总量控制和水体富营养化防治提供科学依据, 并且对同类湖泊和水库的富营养化研究起到借鉴作用.

\section{1 材料与方法}

\section{1 研究区概况}

松花湖即丰满水库 $\left(43^{\circ} 07^{\prime}-43^{\circ} 50^{\prime} \mathrm{N}, 126^{\circ} 45^{\prime}-127^{\circ} 38^{\prime} \mathrm{E}\right)$, 是在松花江小丰满处建水坝而形成的大 型人工湖泊. 流域面积 $43370.8 \mathrm{~km}^{2}$, 回水全长 $180 \mathrm{~km}$, 湖面最宽约 $5 \mathrm{~km}$, 最大水面 $550 \mathrm{~km}^{2}$, 平均水深 $30-$ $40 \mathrm{~m}$; 年人库径流量约 $137 \times 10^{8} \mathrm{~m}^{3}$. 松花湖最大补给水源为松花江上游, 人湖支流 40 余条, 其中最大的为辉 发河, 还有拉法河、旺起河、蚂蚁河、大石头河、小富太河、木箕河和漂河等. 松花湖是长春市和吉林市民众生 活和生产用水的水源地, 此外还有发电、防洪、养鱼、航运、旅游等方面功能. 随着松花湖流域各市县点源污 染治理力度的加大, 非点源污染逐渐显示出对湖区水质越来越严重的影响. 据计算 ${ }^{[6]}$, 松花湖流域中总氮 的污染负荷量为 $0.503 \mathrm{t} /\left(\mathrm{km}^{2} \cdot \mathrm{a}\right)$, 其中非点源负荷量为 $0.36 \mathrm{t} /\left(\mathrm{km}^{2} \cdot \mathrm{a}\right)$; 总磷的污染负荷量为 $0.053 \mathrm{t}$ $/\left(\mathrm{km}^{2} \cdot \mathrm{a}\right)$, 其中非点源负荷量为 $0.041 \mathrm{t} /\left(\mathrm{km}^{2} \cdot \mathrm{a}\right)$. 近几年, 松花湖的有些区域已呈轻度富营养化, 在夏 季以铜绿微囊藻 (Microcystis aeruginosa) 为优势种的条带状水华在局部区域时有发生.

\section{2 松花湖水体总磷、总氮控制目标的确立}

从松花湖分离纯化出夏季的绝对优势浮游藻类——铜绿微囊藻的单藻株,通过室内藻类培养研究磷、 氮浓度 (生物可利用磷和氮浓度) 与其生长的定量关系, 建立其关系曲线, 从以上曲线中找到富营养化发生 的阈值. 藻类培养基本是在 M-11 培养基 ${ }^{[7]}$ 、温度 $25^{\circ} \mathrm{C}$, 照度 $2000 \mathrm{~lx}$, 光暗比为 $12: 12$ 下静止培养 (每天摇 动 4 次). 关于磷和氮的影响试验, 在试验前期, 将处于对数生长期的微囊藻转移到无磷和无氮的 M -11 培 养基中培养 $3 \mathrm{~d}$, 使藻细胞处于磷和氮的饥饿状态. 根据 2002-2004 年松花湖水体中各种形态磷和氮的特 征分析, 得出水体中生物可利用磷和氮与总磷和总氮的定量关系, 从而得到松花湖水体总磷和总氮的控制 目标. 考虑到环境条件的不确定性, 培养条件 (温度、光照等) 尽量与夏季松花湖的实际情况相符 (如温度 $25^{\circ} \mathrm{C}$, 照度 $2000 \mathrm{~lx}$ 等), 以保证所得数据的可靠性.

\section{3 松花湖水体总磷、总氮浓度概率分布类型的判断}

多数情况下, 总磷、总氮浓度概率分布类型可用对数正态分布或正态分布来表示 ${ }^{[8,9]}$. 本文用柯尔莫哥 洛夫一斯米尔诺夫检验 ${ }^{[10]}$ (Kolmogorov-Smirnov Test) 来验证总磷、总氮浓度的分布类型. 另外, 正态分布还 用观测量的直方图与附于图上的正态分布曲线相比较来判断以及用观测量的累积概率 P-P 图进行验 证 $^{[10]}$, 以上检验方法的实现, 依靠 SPSS12.0 软件. 本研究采用 2002-2004 年 (5-10月 ) 测定的松花湖 40 个采样点的总磷和总氮浓度计算.

\section{4 松花湖总磷、总氮水环境容量计算}

根据水环境容量计算原则和风险分析原理,所计算的水环境容量是在水体污染物浓度达标率( 即小于 水质目标的累积频率) 超过 $99.9 \%$ 以上 (理论上应为 $100 \%$ ), 即水体污染物超标风险小于 $0.1 \%$ 时的人湖 量. 如果对现状水体计算的水质达标率小于 $99.9 \%$, 则必须对湖库污染物浓度均值和均方差同步缩小, 采 用蒙特卡罗随机模拟方法 ${ }^{[11,12]}$ 计算新的正态分布参数值 $\mu$ 和均方差 $\sigma$, 使湖库中总磷和总氮浓度小于水质 目标的累积频率为 $99.9 \%$.

由于水体污染物浓度与水体污染物人湖量成正比,因此有 $W_{1}=E_{1} / E \cdot W$, 其中, $W_{1}$ 是在水质浓度达标 率为 $99.9 \%$ 条件下的总磷、总氮人湖量, 也就是湖库总磷、总氮的水环境容量; $W$ 是现状水体中总磷、总氮 
入湖量; $E_{1}$ 是在水质浓度达标率为 $99.9 \%$ 条件下的总磷、总氮浓度均值; $E$ 是现状水体中总磷、总氮浓度均 值. 若湖库污染物浓度分布符合正态分布, 则污染物浓度均值 $\mathrm{E}$ 等于其正态分布函数的参数 $\mu$ (数学期 望), 因此 $W_{1}=\mu_{1} / \mu \cdot W$. 据此可以计算出水质浓度达标率为 $99.9 \%$ 条件下的总磷、总氮允许人湖量, 其 中, 水体总磷和总氮浓度小于水质目标的累积频率的计算以及正态分布参数值 $\mu$ 和 $\sigma$ 的计算依靠于 SPSS12. 0 软件.

\section{2 结果和讨论}

\section{1 松花湖富营养化发生的磷和氮浓度的阈值}

从磷浓度对铜绿微囊藻生长的影响结果 (图 1a) 可知, $\mathrm{PO}_{4}^{3-}-\mathrm{P}$ 浓度 $0.005-0.025 \mathrm{mg} / \mathrm{L}$ 时, 铜绿微囊 藻的最大比增长率随着磷浓度升高而迅速增加, $\mathrm{PO}_{4}^{3-}-\mathrm{P}$ 浓度 $0.025-0.06 \mathrm{mg} / \mathrm{L}$ 时, 最大比增长率随着磷浓 度升高而增加得比较缓慢, 即铜绿微囊藻的最大比增长率在 $\mathrm{PO}_{4}^{3-}-\mathrm{P}$ 浓度 $0.025 \mathrm{mg} / \mathrm{L}$ 时出现了一个拐点, 此时, 铜绿微囊藻的最大比增长率很大, 为 $0.61 \mathrm{~d}^{-1}$, 达到了最高的 $\mu_{\max }$ 的 $95 \%$, 即松花湖水体在 $\mathrm{PO}_{4}^{3-}-\mathrm{P}$ 浓 度 $0.025 \mathrm{mg} / \mathrm{L}$ 以上时, 进人富营养化阶段. 在 $\mathrm{PO}_{4}^{3-}-\mathrm{P}$ 浓度 $0.06-0.6 \mathrm{mg} / \mathrm{L}$ 时, 藻类一直以最高的最大比 增率增长, 在 $\mathrm{PO}_{4}^{3-}-\mathrm{P}$ 浓度达到 $0.6 \mathrm{mg} / \mathrm{L}$ 以上后, 铜绿微囊藻的增长速率减缓, 生长量持平或呈下降的趋 势, 也就是湖泊处于非响应阶段. 因此, 为防止松花湖富营养化的发生, 应使湖水中可利用磷的含量控制在 $0.025 \mathrm{mg} / \mathrm{L}$ 以下. 美国 EPA 建议总磷浓度 $0.05 \mathrm{mg} / \mathrm{L}$ 和正磷酸盐浓度 $0.025 \mathrm{mg} / \mathrm{L}$ 是湖泊和水库磷浓度的 上限 ${ }^{[13]}$, 这与本研究的结论基本相符.
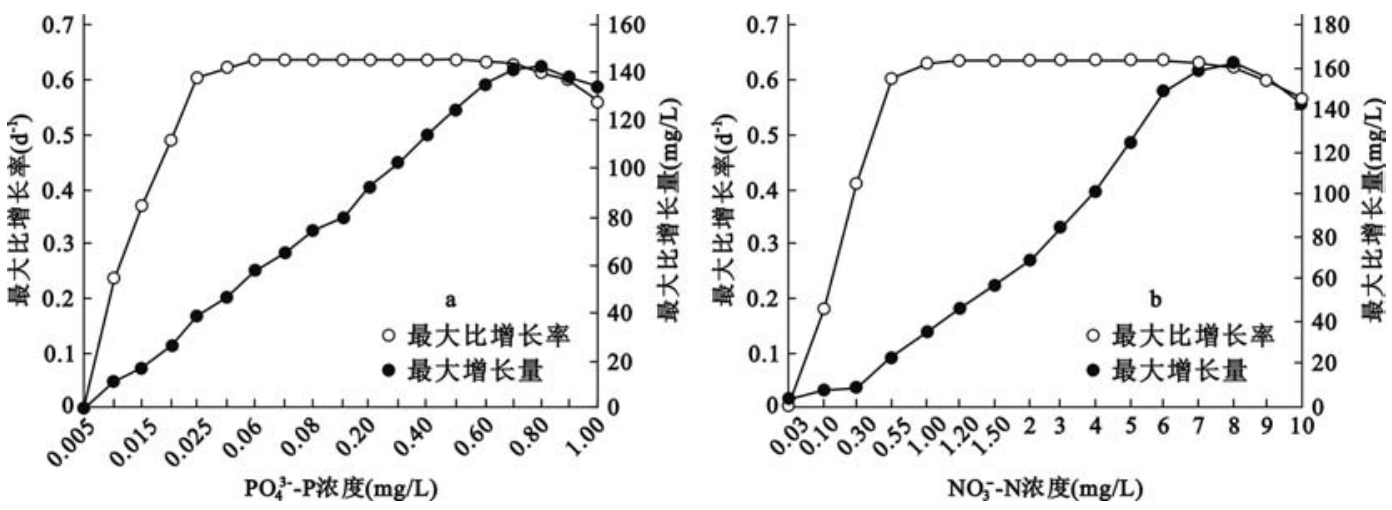

图 1 磷 (a) 和氮 (b) 对铜绿微囊藻最大比增长率和最大增长量的影响

Fig. 1 Effect of phosphorus concentration and nitrogen concentration on the maximum specific growth rate and the maximum growth of the Microcystis aeruginosa

从氮浓度对铜绿微囊藻生长的影响结果 (图 1b) 可知, $\mathrm{NO}_{3}^{-}-\mathrm{N}$ 浓度 $0.03-0.55 \mathrm{mg} / \mathrm{L}$ 时, 铜绿微囊藻 的最大比增长率随着氮浓度升高而迅速增加, 在 $\mathrm{NO}_{3}^{-}-\mathrm{N}$ 浓度 $0.55-1.2 \mathrm{mg} / \mathrm{L}$ 时, 最大比增长率随着氮浓 度升高而增加得比较缓慢, 即铜绿微囊藻的最大比增长率在 $\mathrm{NO}_{3}^{-}-\mathrm{N}$ 浓度 $0.55 \mathrm{mg} / \mathrm{L}$ 时出现了一个拐点, 此 时, 铜绿微囊藻的最大比增长率很大, 为 $0.60 \mathrm{~d}^{-1}$, 达到了最高的 $\mu_{\max }$ 的 $95 \%$, 即松花湖水体在 $\mathrm{NO}_{3}^{-}-\mathrm{N}$ 浓度 $0.55 \mathrm{mg} / \mathrm{L}$ 以上时, 进人富营养化阶段. $\mathrm{NO}_{3}^{-}-\mathrm{N}$ 浓度 $1.2-6 \mathrm{mg} / \mathrm{L}$ 时, 藻类一直以最高的最大比增率增长, 在 $\mathrm{NO}_{3}^{-}-\mathrm{N}$ 浓度达到 $6 \mathrm{mg} / \mathrm{L}$ 以上后, 铜绿微囊藻的增长速率减缓, 生长量持平或呈下降的趋势, 也就是湖泊 处于非响应阶段. 因此, 为了安全起见, 为防止松花湖富营养化的发生, 应使湖水中藻类可利用氮的含量控 制在 $0.55 \mathrm{mg} / \mathrm{L}$ 以下.

从 $2002-2004$ 年松花湖水体中各种形态磷的含量可知, 总磷中的 $51.51 \%$ 为可溶性的, 其中可溶性磷 酸盐 $\left(\mathrm{PO}_{4}^{3-}-\mathrm{P}\right)$ 占总磷的 $18.94 \%$, 可溶性的有机磷为 $32.57 \%$. 一般说来, 溶解态无机磷被认为是藻类最重 要的磷源, 近来的研究表明, 藻类也可以利用溶解的有机磷, 特别是在磷限制的湖泊和某些海域, 溶解态有 
机磷的生物可利用性显得更为重要, 在对溶解态有机磷的利用中, 碱性磷酸酶的活性都有所变化 ${ }^{[14-17]}$. 在 许多湖泊中, 溶解性有机磷的浓度要比溶解性的反应磷高 1 倍以上, 其中大约 $60 \%$ 左右的溶解性有机磷可 以被碱性磷酸酶水解后, 用于藻类的生长 ${ }^{[18]}$. 松花湖水体中 $\mathrm{PO}_{4}^{3-}-\mathrm{P}$ 含量为 $0.014 \mathrm{mg} / \mathrm{L}$, 低于太湖水体中碱 性磷酸酶的作用阈值 ${ }^{[19]}$, 所以夏季, 松花湖水体中的藻类和细菌体中的酶被诱导大量产生, 水体中的有机 磷化合物被水解, 释放出无机磷, 使水体中藻类的生长和繁殖得以持续. 根据松花湖水体中 $\mathrm{PO}_{4}^{3-}-\mathrm{P}$ 和溶解 性有机磷与总磷的比例可以计算出松花湖水体中总磷的 $38.46 \%$ 为藻类可利用磷.

松花湖水体中无机氮占总氮的 $65.26 \%$, 其中, 硝酸盐氮占无机氮的 $56.24 \%$,氨态氮占无机氮的 $40.82 \%$, 亚硝酸盐氮的含量很低, 为 $0.033 \mathrm{mg} / \mathrm{L}$, 有机氮的含量占总氮的 $34.74 \%$. 虽然藻类也可利用有机 氮, 但是松花湖以磷为第一限制因子 ${ }^{[20]}$, 藻类以利用溶解的无机氮为主, 即松花湖水体中的可利用氮占总 氮的 $65.26 \%$. 结合上面的结论可以得出松花湖富营养化发生的國值为: 总磷含量 $0.065 \mathrm{mg} / \mathrm{L}$, 总氮含 量 $0.843 \mathrm{mg} / \mathrm{L}$.

\section{2 松花湖水体总磷、总氮概率分布特征}

分别对 2002-2004 年松花湖水体中总磷和总氮含量进行柯尔莫哥洛夫一斯米尔诺夫检验,得出总氮 和取自然对数后总磷的双尾渐进显著性概率分别为 0.304 和 0.604 , 远大于 0.05 , 因此松花湖水体中总氮 和总磷分别服从正态分布和对数正态分布.

对松花湖水体中 $2002-2004$ 年的总磷含量取自然对数后, 可得到松花湖水体总磷含量的频数分布图 (图 2a) 和 P-P 正态分布检验图 (图 2b), 从中可知松花湖水体总磷含量取自然对数后基本是正态分布, 即 总磷含量符合对数正态分布. 从图 $2 \mathrm{a}$ 可知, 其正态分布参数值为: $\mu=-2.628$, 标准差 $\sigma=0.369$. 松花湖水 体中 $2002-2004$ 年总氮含量的频数分布及 P-P 正态分布检验结果和总磷类似,也基本是正态分布,其正态 分布参数值为: $\mu=1.738$, 标准差 $\sigma=0.444$ (图略).
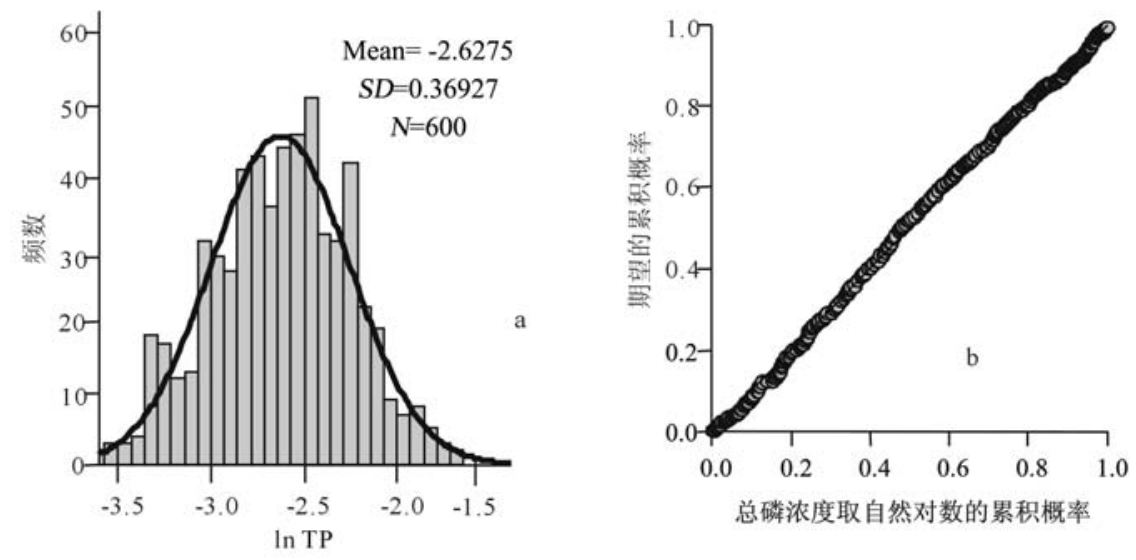

图 2 松花湖水体总磷含量频数分布图 (a) 和 P-P 正态分布检验图 (b)

Fig. 2 The frequency distribution and examination of P-P normal distribution of TP content in Lake Songhua

\section{3 松花湖总磷、总氮水环境容量计算}

2.3.1 松花湖总磷水环境容量计算 从松花湖水体总磷浓度累积频率的计算可知, 在现状水质条件下, 总 磷浓度达标率 (标准为 $0.065 \mathrm{mg} / \mathrm{L}$ ) 为 $38.33 \%$, 要满足达标率为 $99.9 \%$ 的目标, 必须减小水体中总磷浓度. 采用蒙特卡罗随机模拟方法计算得出: 当总磷浓度对数正态分布参数值同步减少到 $\mu_{1}=-3.546, \sigma_{1}=$ 0.275 时, 可满足此目标 (图 3a 和图 3b).

对一个比较稳定的湖泊来说, 湖泊流域中的污染物排放量与污染物的人湖量成正比, 即污染物的排放 量越多,其入湖量就越多,所以有: $\quad W_{\text {排 } 1}=E_{1} / E \cdot W_{\text {排 }}$.

对于对数正态分布来说, 其均值 $E$ 与分布函数的参数 $\mu$ 的关系为: $E=\mathrm{e}^{u}$. 
通过计算, 1999 年松花湖流域总磷的排放量为 $2283.09 \mathrm{t} / \mathrm{a}$, 总磷年平均浓度为 $0.031 \mathrm{mg} / \mathrm{L}, 2002-$ 2004 年总磷的 $E$ 为 0.0724 , 可以算出 $2002-2004$ 年的总磷排放量为 $5332.12 \mathrm{t} / \mathrm{a}$, 在达标率为 $99.9 \%$ 的条 件下, 松花湖流域总磷的最大允许排放量为 $2123.78 \mathrm{t} / \mathrm{a}$, 松花湖流域现状排放量为 $5332.12 \mathrm{t} / \mathrm{a}$, 因此, 必须 采取污染控制措施, 使总磷排放的削减量达到 3208.34 t/a.
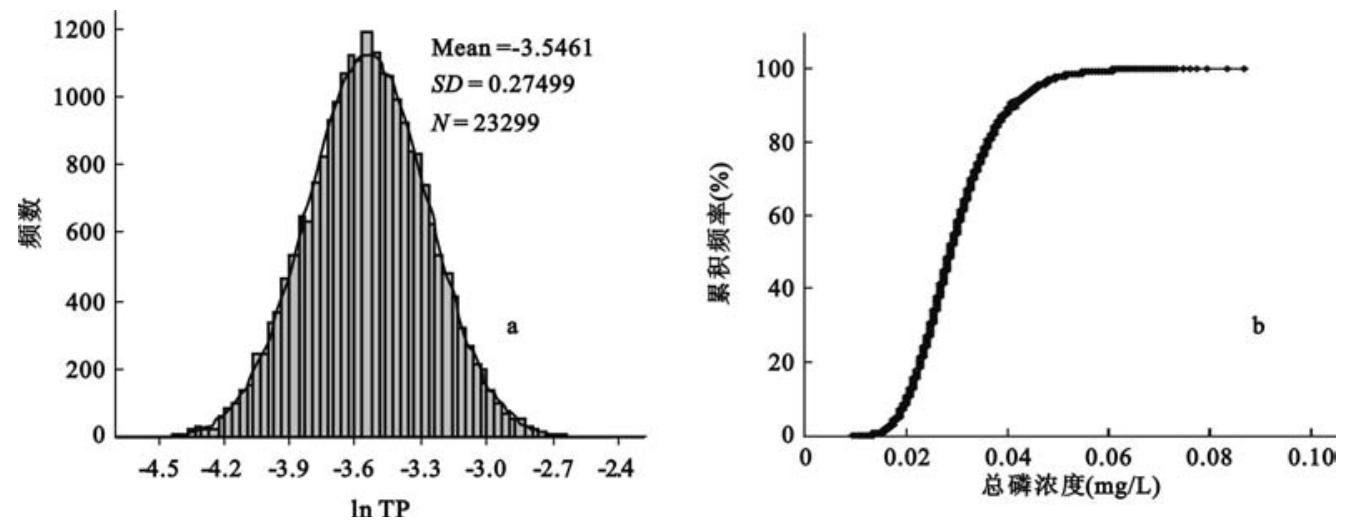

图 3 满足水质目标时总磷含量频数分布 (a) 和累积频率分布 $(\mathrm{b})$

Fig. 3 The frequency distribution and accumulation frequency distribution of TP content if meet water quality target

2.3 .2 松花湖总氮水环境容量计算 从松花湖水体总氮累积频率的计算可知, 在现状水质条件下, 总 氮浓度达标率 (标准为 $0.843 \mathrm{mg} / \mathrm{L}$ ) 为 $2.17 \%$, 接近 0 , 要满足达标率为 $99.9 \%$ 的目标, 必须减小水体中总 氮浓度. 采用蒙特卡罗随机模拟方法计算, 得出: 当总氮浓度正态分布参数值同步减少到 $\mu_{1}=0.475, \sigma_{1}=$ 0.122 时, 可满足此目标 (图 4a 和图 4b).

根据计算可知, 1999 年松花湖流域总氮排放量为 $21855.37 \mathrm{t} / \mathrm{a}$, 水体中总氮年平均浓度为 $1.480 \mathrm{mg} / \mathrm{L}$, $2002-2004$ 年总氮的 $\mu$ 为 1.7384 , 可计算出 $2002-2004$ 年总氮排放量为 $25667.73 \mathrm{t} / \mathrm{a}$. 在满足松花湖水质 总氮浓度达标率为 $99.9 \%$ 的条件下, 松花湖流域的最大允许排放总氮量为 $7018.82 \mathrm{t} / \mathrm{a}$, 松花湖流域现状排 放量为 $25667.73 \mathrm{t} / \mathrm{a}$, 已大大超标, 这是造成松花湖现状水质恶化、出现轻度富营养化的主要原因之一, 因 此,必须采取控制措施, 使总氮排放的削减量达到 $18648.91 \mathrm{t} / \mathrm{a}$.
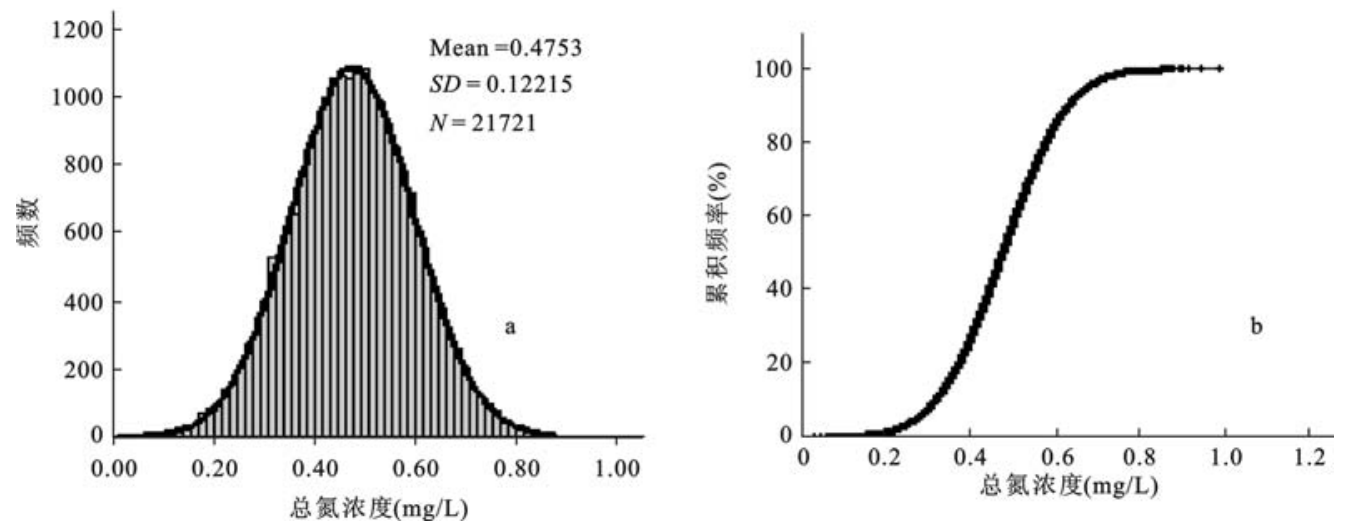

图 4 满足水质目标时总氮含量频数分布 $(\mathrm{a})$ 和累积频率分布 $(\mathrm{b})$

Fig. 4 The frequency distribution and accumulation frequency distribution of TN content if meet water quality target 


\section{3 结论}

本文通过室内培养确定松花湖富营养化发生的阈值以及在分析水体中磷、氮浓度实际分布规律的基础 上, 提出了以风险分析理论和蒙特卡罗模拟方法为基础的确定湖库水体磷、氮环境容量的计算方法. 本方法 建立在湖库水体实际自净规律基础之上, 避开了难以准确确定的污染物降解系数等参数, 对于影响因素复 杂、不确定性因素多的磷、氮水环境容量的计算具有实用价值. 通过松花湖的计算, 说明现状的松花湖水体 中, 总磷和总氮都已超标, 松花湖流域总磷和总氮的最大允许排放量为: $2123.78 \mathrm{t} / \mathrm{a}$ 和 $7018.82 \mathrm{t} / \mathrm{a}$, 为了使 松花湖富营养化发生的概率在 0.001 以下, 总磷和总氮需要分别削减 3208.34 t/a 和 18648.91 t/a.

\section{4 参考文献}

[1] Zhou Q, Gibson C E, Foy R H. Long-term changes of nitrogen and phosphorus loadings to a large lake in North-West Ireland. Water Research, 2000, 34(3): 922 - 926.

[2] 金相灿. 湖泊富营养化控制和管理技术. 北京: 化学工业出版社, 2001:1-14.

[3] 赵生才. 我国湖泊富营养化的发生机制与控制对策. 地球科学进展, 2004, 19(1): $138-140$.

[4] 谢 平, 黎红秋, 叶爱中. 基于经验频率曲线的湖泊富营养化随机评价方法及其验证. 湖泊科学, $2004,16(4): 371-376$.

[5] 刘 凌,崔广柏. 湖泊、水库水体氮、磷允许纳污量定量研究. 环境科学学报, 2004, 24 (6): 1053 $-1058$.

[6] 王 宁. 松花湖流域非点源污染研究. 中国科学院东北地理与农业生态研究所博士论文, $2001: 97$ -103 .

[7] 南條吉之, 細井由彦, 城戸由能等. 湖山池における藻類増殖の制限物質について. 水環境学会, 2000, 23(11) : $690-696$.

[8] 胡二邦. 环境风险评价. 北京: 中国环境科学出版社, $2000: 254-302$.

[9] Jerald L S. Environmental modeling-fate and transport of pollutants in water, air, and soil. New York: John Wiley \& Sons, 1996 : $259-269$.

[10］郝黎仁,樊 元, 郝哲欧等. SPSS 实用统计分析. 北京: 中国水利水电出版社, $2003: 255-265$.

[11] Song J L. Analysis of light-emitting diodes by Monte Carlo photon simulation. Appl Opt, 2001, 40 (9) : $1427-1437$.

[12] 姚 宏, 李圭白, 张景成等. 蒙特卡罗方法在水污染控制理论中的应用前景. 哈尔滨工业大学学报, $2004,36(1)$ : $129-131$.

[13] 李小平. 美国湖泊富营养化的研究和治理. 自然杂志, 2002, 24(2): 63-68.

[14] 王海黎,洪华生. 海洋环境中溶解有机磷的生物活性初探. 厦门大学学报 (自然科学版), 1995,34 (3) : $425-420$.

[15] 周易勇,付永清. 水体磷酸酶来源、特征及其生态学意义. 湖泊科学, 1999, 11(3): $274-279$.

[16] 黄世玉, 黄邦钦. 不同磷源对藻类生长及其生化组成的影响. 台湾海峡, 1997, 16(4): 458 - 464.

[17] 高 光, 秦伯强, 朱广伟等. 太湖梅梁湾中碱性磷酸酶的活性及其与藻类生长的关系. 湖泊科学, $2004, \mathbf{1 6}(3)$ : $245-251$.

[18] Hantke B, Fleischer P, Domany I, et al. P release from DOP by phosphatase activity in comparison to P excretion by zooplankton. Studies in hardwater lakes of different trophic level. Hydrobiologia, 1996, 317 : $151-162$.

[19] 高 光, 高锡芸, 秦伯强等. 太湖水体中碱性磷酸酶的作用阈值. 湖泊科学, 2000, 12(4): $353-359$.

[20] 王 霞, 吕宪国,张学林等. 松花湖富营养化现状及其影响因素分析. 湿地科学, 2004, 2(4): 273 -278 . 